with moderate force, the compressions being made to imitate the systolic and diastolic action of the heart. In 31 cases, or $70 \%$, life was restorel. In chloroformed dogs under the same conditions, $76 \%$, and in dogs shocked by the electric current, $14 \%$ were brought back to life. An attempt to try massage of the heart was made on the borly of an alcoholic who had committed suicide by hanging, but, without success, as might have been expected.

Statistics gleaned from various sources at home and abroad by l'rof. Wm. W. Keen, show that of 28 eases of apparent death in the human being, during ehloroform narcosis, 42 recovered by massage of the heart. But this treatment should not be relied upon alone. Artificial respiration should also be cairried on and the patient should receive sufficient oxygen. l'or the purpose of restoring vasomotor tone adrenalin should be employed."

In the great-zeal to collect statistics on this interesting subject, doubtless many of them come from the same sources. Thus lamermant hats collected 25 eases of whom 4 were restored to life. ${ }^{7}$

Matuclair and Zezas report 28 cases with 6 successful results.

Three methods are employed to do massage of the heart:

1. Incising the anterior wall of the ehest so that the hand ean grasp the heart.

2. Incising the diaphragm and then passing the hand up from the aldominal cavity.

3. Seizing the heart; through the diaphragm without cutting it. In syncope the diaphragm is relaxed enough to render the last method easy. It has given the greatest percentage of recoveries (5 out of 9 ). It is the least mutilating and the only one that should be employed. Although the number of deaths scems large it should be remembered that all the casses saved would doubtless have died without the use of this method.

When babies are born, if their respiration and circulation are at fault, they are promptly rubbed and slapped without waiting for a diagnosis and ustually with the result of bringing them around all right. So the poet of the future may have a chance to express himself with regard to massage somewhat as follows:

When this world you enter if you're gasping for breath, "lis the first thing they do to save you from death; If too soon you would leave this terrestrial sphere: "Ilis the last, thing tlary do to keep you long here.

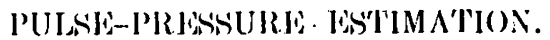

HY JAMEA J. PUTNAM, M.D., OF MOSTON.

HaviNa been interested for some time past in the measurement of pulse-pressure, and having striven to find the best method of estimating its legree by the finger, in the alsence of instruments, I have decided upon the following plan as decidedly preferable to any other and as sus-

'Ther. Gaz., Philadelphig, Npril 15, 1904.

7 liev. de (hir., No. 3, 1906

aluid., 111 , i, igrti. ceptible of being made, through practice, of much value.

The physician, placing himself opposite to his patient, should lay the pulp of his extended (right) forefinger over the patient's (right) radial artery, at the same time interlocking his forefinger and thumb with the forefinger and thumb of the patient's hand. With his disengaged (left) hand, the physician should then grasp the patient's relaxed arm, just above the ellow and just below the swell of the biceps, in such a way that with his thumb he may compress the patient's brachial artery against the underlying humerus, while with his fingers he may make counter-pressure on the outer portion of the arm. It becomes, then, very easy to estimate just the amount of muscular effort that is required to olose the brachial artery so that the pulse is no longer to be felt by the finger at the wrist, and this effort measures the maximal pressure of the pulse. Even the minimal pressure, that is, the point at which the impulse in the two arteries becomes the same as the compressing thumb is raised, can be estimated better with the aid of the brachial artery, in this fashion, than with the radial alone, and fairly well, provided the physician has been accustomed to take such pressures accurately with an instrument, suited for the purpose.

It is astonishing to find what a difference there is between the tension which the compressing thumb and fingers must overeome in the case of a compressible brachial artery and that in the case of an artery altered through hypertrophy. In well-marked arteriosclerosis the amount of pressure required for complete closure may be so great that the effort exerted in overeoming it must be considerable.

\section{ßzew Fnstrument.}

\section{A NEW JOEVICE FOR AIJJUS'TING THE FOREHEAI) MIRROR.}

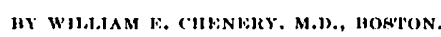

IN operating on the nose and throat I have often desired some form of applianee by which the forehead mirror eould be easily and aseptically adjusted. It has heen customary to use pieces of aseptic gauze, but this has not been wholly satisfactory.

It occurred to me that a steel spring clamp might be made which could be boiled with the other instruments, and when needed slipped on to the side of the mirror and left there during the operation, therely giving the operator an aseptic handle which he could use at will to move the mirror in or out of position.

I have had several made and perfected and now present this one which I have ealled the universal head mirror adjuster.

All users of the forehead mirror will appreciate it. It may be easily applied, fits large and small mirrors and will cling tightly so that the mirror 
may be moved in any direction. Inring ordi-/cussion of I)r. Posey's paper as to the difficulty nary examinations it, may also be used so as to of recognizing sinus disease. I wish to call

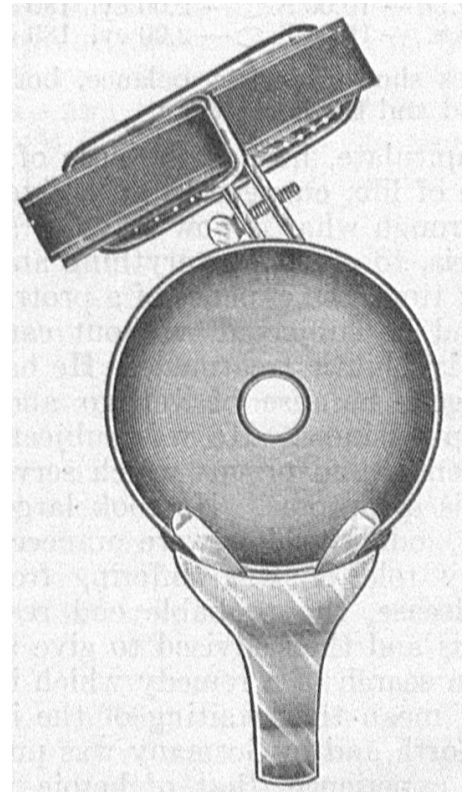

avoid finger prints on the mirror. 'This will be appreciated by many patients.

The instrument should be applied opposite the attachment to the heablband.

codman and shurtleff have made the aljuster for me.

\section{Eliniral țepartment.}

THE OCULAR ANI) (BENERAL SYMPTOMS IN NASAL, OBST'RUGTION. THE REPOR'T OH AN UNUSUAI, CANE.

HY НA HKY (. PALKK:H, M.1)., BOSTON,

Clinical Asaistant Wasachusetts Charita'le Eye and Ear Infirmory; Instructor in Ophthalmology. Yufta Collece Medical School, etc.

A river reading Dr. Posey's exhaustive article presented before the Section on Ophthalmology of the American Medical Association in July, 1905, one feels there is little new to offer, showing the intimacy of the relation between the nose and its accessory sinuses and the eye. Although his article dealt with "The ocular symptoms of affections of the accessory sinuses of the nose," I wish he had given more space to those cases of simple nasal obstruction which give rise to ocular symptoms, as severe, and eertainly as hard to combat, without operative interference, as those of sinus troubles. I refer to the ocular symptoms caused by enlarged turbinates, spurs, deviations of the septum, etc.

There is rarely a day passes in the refraction room of the Massichusetts (hatritable bye and Lar Infirmary without the appearane of several cases which, from the chatrater of their symptoms and the nature of their refractive errors, suggest the necessity of a nasial examination. In this connection I should like to state my hearty agrecment, with Dr. Wlward Jackson in his disattention to the equal difficulty in recognizing cases of simple nasal obstruction, for many cases are reported back as negative by the rhinologist where, from the nature of the symptoms, you are sure a pathological condition exists in the nose, and which will usually be revealed at some subsequent examination.

'The greater number of nasal cases have, at some time or another, definite eye symptoms, and the time has come when the oculist must insist, in order to get good results, on the intellirent (o)-(operation of the rhinologist, or else be himself forced to treat the nasal conditions which give rise to ocular symptoms of greater or less severity. Few rhinologists recognize the fact that simple soft turbinate contact with the septum will, in many individuals, give rise to symptoms which will not be relieved at all, or only in part, by correcting errors of refraction or defects in the muscle balanec.

The case I wish to report is of interest from the severity and the unusual character of the symptoms presented both ocular and general. My notes follow:

February, 1900. Mr. J. R. consulted me in regard to persistant diplopia and vertigo. His age, fortyone years, married, two healthy children. No history of wife having had a miscarriage. Had always been a hard worker. (ieneral health always excellent up to 1899. Denies gonorrhea or syphilis. Myopic as long as he could rememlere, and havl worn glasses constantly from his early youth. His eyes had given him no trouble beyond the handicap of his myopia until 1899 , when he developed diplopia. I wish to state here parenthetically that $\mathrm{Mr}$. $\mathrm{R}$. is a man of keen intelligence and not of the neurasthenic type. His diplopia at that time varied in amount for 20 to 60 prism degrees aceording to the notes of his oculist which he had with him. 'The diplopia was homonomous, i.e., esophoria, which in itself is extremely unusual in as high a degree of myopia, and his binocular vision was always obtained readily with prisms. His myopia was at that time undercorrected. He was wearing 0.1 . -13.00 s. $\odot-2.00 \mathrm{cyl}$. $\mathrm{x} 180^{\circ}$. $0 . \mathrm{s} .-12.00 \mathrm{~s} . \leftrightharpoons-2.00$ cyl. $\times 180 .-$ so full correction $-15.00 \mathrm{~S} . \subseteq-2.50$ cyl. $x 180^{\circ}$. out was given, combined with a $6 \Delta^{\circ}$ base out in both eyes. 'This produced a great diseomfort increasing, if possible, diplopia and caused general symptoms, or at least general symptoms appeared at this time, such as numbness of the face, abdominal shooting pains, and the loss of muscle reflexes. He was allowed to wear his weaker lenses without prisms. His rase progressed with little or no improvement, so he was taken to an alienist, who examined fully into his history as his oculist had done, and a constitutional cause of any sort eould not, be found. The slightest ehanee of syphilis denied except from possible imnocent cause, about which the patient had no knowledge. He was told he had irregular tabes, advised to give up business and either rough it out. West for a year or go abrond. He chose burope and shortly after his arrival consulted a prominent oculist in (iermany, who insisted he had syphilis and proceeded to give him a severe course of mercurial inunctions, potassium iodide, which by the way he had had in teaspoonful doses three times a day before leaving this country, and quantities of Blaud's pills. 'This heroic treatment sucreeded simply in the 